\title{
Does Aberrant Right Hepatic Artery Influence the Surgical Short- and Long-term Outcome of Pancreatoduodenectomy?
}

\author{
DANIELE CROCETTI ${ }^{1}$, PAOLO SAPIENZA ${ }^{1}$, PAOLO OSSOLA $^{1}$, \\ MARIARITA TARALLO ${ }^{1}$, GIUSEPPE CAVALLARO ${ }^{1}$, RAFFAELE SERRA ${ }^{2}$, \\ RAFFAELE GRANDE ${ }^{1}$, ANDREA MINGOLI ${ }^{1}$, ENRICO FIORI ${ }^{1}$ and GIORGIO DE TOMA ${ }^{1}$ \\ ${ }^{1}$ Pietro Valdoni Department of Surgery, Sapienza University of Rome, Rome, Italy; \\ ${ }^{2}$ Department of Medical and Surgical Sciences, Magna Graecia University, Catanzaro, Italy
}

\begin{abstract}
Background: Variations in vascular anatomy in pancreaticoduodenectomy for adenocarcinoma of the pancreatic head, aberrant right hepatic artery ( $\alpha R H A)$ being the most frequent, may influence oncological outcome, surgical complexity, intra- and postoperative complications, and overall 5-year disease-free and survival rates. Materials and Methods: Between January 1988 and January 2018, 297 consecutive patients underwent pancreaticoduodenectomy at our Institutions and were divided into two groups: Group 1 patients were affected with $\alpha R H A$; group 2 were without this vascular anomaly. The groups were retrospectively compared to identify differences in preoperative characteristics and intraoperative course, postoperative morbidity and mortality and long-term disease-free interval and overall survival. Cox regression analysis was used to investigate the role of variables statistically significant at univariate analysis in the short-and long-term outcomes. Results: Overall 44 (15\%) patients had $\alpha R H A$. No differences in patient characteristics were reported. The mean operative time was $451 \pm 58$ minutes for group 1 and $317 \pm 27$ minutes for group $2(p<0.001)$, whereas mean blood losses were $729 \pm 488 \mathrm{ml}$ and $508 \pm 119 \mathrm{ml}$, respectively $(p<0.001)$. Group 1 patients had a longer stay in intensive care when compared to patients of group 2 (mean $5 \pm 2$ versus $4 \pm 2$ days, respectively; $p<0.001)$. Furthermore group 1 patients had a significant longer hospitalization when compared to those of group 2 (mean $17 \pm 5$ versus $15 \pm 3$ days, respectively; $p<0.006$ ).
\end{abstract}

This article is freely accessible online.

Correspondence to: Paolo Sapienza, MD, Ph.D., Associate Professor of Surgery, Pietro Valdoni Department of Surgery, Sapienza University of Rome, Policlinico Umberto $I^{\circ}$, Viale del Policlinico, 151, 00161 Rome, Italy. Tel: +39 0649972780, Fax: +390649970794, e-mail: paolo.sapienza@uniroma1.it

Key Words: Pancreatoduodenectomy, aberrant right hepatic artery, vascular anomalies.
No other significant differences were observed between the two groups. Cox regression analysis showed that independently of the presence of $\alpha R H A$, the factors negatively affecting the 5 -year survival rate were blood loss $(p<0.001)$ and length of stay in intensive care $(p<0.001)$. Discussion: $\alpha$ RHA increases the surgical complexity of pancreatoduodenectomy, negatively affecting intraoperative blood loss, length of operation, length in intensive care and hospitalization, but does not influence long-term survival and disease-free rates.

Vascular anatomical variations in the upper abdomen are common and numerous in the general population (1-6). Right hepatic artery anomalies are divided into accessory and aberrant: the former is an additional artery that provides hepatic vascularization, while the latter is a branch of the superior mesenteric artery that is the only blood supply to the liver $(3,7,8)$. A right hepatic artery branching directly from the superior mesenteric artery is the most common variation, ranging in frequency from $11-26.5 \%(9,10)$.

The identification of an anomalous hepatic artery course is mandatory during pancreatic surgery (3) because the presence of aberrant right hepatic artery ( $\alpha$ RHA) may compromise oncological clearance or, on the other hand, more radical procedures may result in an increased operative time, intraoperative blood loss, intra- and postoperative complications, length of stay and overall mortality $(3,5,10,11)$.

A deep knowledge of vascular anatomy in the pancreatic region is required in order to deploy all necessary measures to preserve essential vascular structures and to avoid accidental lesions or ligatures that could lead to hepatic and biliary ischemia $(5,10,12-14)$. Recognizing $\alpha \mathrm{RHA}$ is essential before pancreatoduodenectomy (PD) (15, 16); major pancreatic resection for malignancy is in fact challenging in the presence of $\alpha \mathrm{RHA}$, thus necessitating the non-trivial choice between preserving the artery or obtaining an $\mathrm{R} 0$ resection (10).

In the present study, we investigated the influence of this abnormal vascular course of the artery on oncological 
radicality, surgical complexity, intra- and postoperative complications, 5-year survival and disease-free rates.

\section{Materials and Methods}

Two-hundred-ninety-seven consecutive patients affected with a preoperative histological diagnosis of pancreatic head carcinoma undergoing PD between January 1988 and January 2018 were retrospectively enrolled encompassing the entire series of our Institutions. Patients with non-resectable lesions or patients who underwent distal pancreatectomy were excluded from the present analysis. This report is in accordance with the STROBE statement checklist of reporting on cohort studies (17). A retrospective analysis of patients' charts and outpatient records was carried out according to the principles laid down in the Declaration of Helsinki. Formal ethic approval from our Institutional Research Committee was not required for retrospective collection of anonymous data on patients treated with already described surgical techniques. However, written informed consent for treatment and the analysis of data for scientific purpose is obtained from all patients at our Institution independently of future studies.

Clinical, pathological, intra- and postoperative data, and longterm outcomes were collected in a computerized database. Demographic data and information on symptoms and comorbidity were retrieved from the hospital charts. Comorbidities were defined as follows: Familiality specifically for pancreatic cancer, active smoking, anamnestic cardiac disease (prior myocardial infarction, stable or unstable angina, or ST segment alteration on electrocardiogram), hypertension (diastolic blood pressure, $\geq 85$ $\mathrm{mmHg}$ ), renal disease (blood urea nitrogen $>7.1 \mathrm{mmol} / \mathrm{l}$; creatinine level $>266 \mu \mathrm{mol} / \mathrm{l}$; creatinine clearance $<50 \mathrm{ml} / \mathrm{min}$ ), pulmonary disease $\left(\mathrm{PO}_{2}<60 \mathrm{mmHg} ; \mathrm{PCO}_{2}>50 \mathrm{mmHg}\right.$; pulmonary function tests $<80 \%$ of predicted; tested with arterial blood gas test and spirometry), and obesity (body mass index $>20 \%$ of ideal). All patients underwent contrast-enhanced thoracic and abdominal computed tomography, abdominal ultrasonography, and complete blood tests. Biliary tree examination was performed with endoscopic retrograde cholangiopancreatography or magnetic resonance imaging. No patients underwent preoperative biliary drainage. Vascular abnormalities were assessed preoperatively with computed tomographic angiography (CTA), or intraoperatively and these data were retrieved from the hospital chart.

Subsequently, the patients were divided into two groups based on the presence of $\alpha$ RHA (group 1) or normal vascular anatomy (group 2). Ten (3\%) patients had other vascular anomalies (i.e. replaced left hepatic artery from left gastric artery) and were excluded from the present analysis. The two groups were compared to identify differences in demographic and clinical data [including the American Society of Anesthesiologists score (18)], intraoperative findings, pathological results, postoperative events [including biliary and pancreatic fistula classified according to the International Study Group on Pancreatic Fistula (19)] and 5-year disease-free interval and survival rates.

Serum samples [bilirubinemia, alkaline phosphatase, $\gamma$ glutamyltranspeptidase, carcinoembryonic antigen (CEA), tissue polypeptide-specific antigen (TPA), and carbohydrate antigen 19-9 (CA19-9)] were obtained by direct venipuncture of an antecubital vein of the arm at patient's admission to hospital before surgery.

All patients received prophylactic antibiotics preoperatively (cefotaxime sodium and metronidazole). Octreotide or gabesate mesylate was never administered. Proton pump inhibitors were administered during the postoperative period when indicated. All surgical procedures were performed by experienced abdominal and pancreatic surgeons with vascular competence.

End points of the study. Primary end points considered were intraoperative outcomes (length of surgery, blood losses) and postoperative results (length of stay in intensive care unit, length of hospitalization, incidence of surgical and medical complications). The secondary end points were the 5-year disease free-interval and survival rates.

Statistical analysis. Our data were analyzed with SPSS Ver. 25.0.0.1 (SPSS Chicago, IL, USA). All results are expressed as the mean \pm standard deviation, or as frequencies. Due to sample sizes, non-parametric tests were applied. The Mann-Whitney $U$-test was used to analyze continuous variables. Chi-square test or Fisher's exact test were used to study categorical variables. Survival rates, and disease-free intervals were assessed by the Kaplan-Meier method and comparison between curves was performed with the log-rank test. Standard error (SE) of survival rates, and disease-free intervals were estimated at each censored case. Cox regression analysis was applied to assess the eventual influence of the aberrant or normal course of the hepatic artery in intra- and postoperative results and 5-year survival and disease-free rates. Variables that significantly differed at a level of significance $p<0.05$ were entered into the model, whose goodness of fit was assessed by the HosmerLemeshow test. Differences with $\alpha$-level of less than 0.05 were considered statistically significant.

\section{Results}

Clinical findings. There were 178 (54\%) males and 119 $(36 \%)$ females. The mean age at presentation was $68 \pm 8$ years (range $=57-81$ years; median $=69$ years). Demographic and clinical data are summarized in Table I. No significant differences between the two groups were noted.

Diagnostic and radiological findings. Forty-four (15\%) patients had an $\alpha$ RHA arising from the superior mesenteric artery, the remaining 253 (85\%) had normal vascular anatomy. In 37 (84\%) patients, $\alpha$ RHA was diagnosed during the preoperative noninvasive investigation whereas in seven $(16 \%)$ was an intraoperative finding. In $18(41 \%)$ cases, the $\alpha$ RHA ran along the posterior surface of the pancreatic head to the posterolateral face of the hepatoduodenal ligament, and in all patients was preserved; in the remaining 26 (59\%), the $\alpha$ RHA followed a ventral course with respect to the head of the pancreas.

Intraoperative findings. Two-hundred and one (68\%) patients underwent a classical Whipple's procedure, and 96 (32\%) pylorus-preserving PD.

The abnormal course of the artery was preserved in $33(75 \%)$ cases, whereas in eight (18\%) the $\alpha$ RHA was intentionally transected with primary anastomosis to the gastroduodenal artery stump. In three cases (7\%), a great saphenous vein graft 
Table I. Main features and statistical analysis of demographics and clinical data of the two groups of patients.

\begin{tabular}{|c|c|c|c|}
\hline & $\begin{array}{l}\alpha \mathrm{RHA} \\
(\mathrm{n}=44)\end{array}$ & $\begin{array}{c}\text { Non- } \alpha \text { RHA } \\
\quad(\mathrm{n}=253)\end{array}$ & $p$-Value \\
\hline \multicolumn{4}{|c|}{ Gender, n (\%) } \\
\hline M & $30(68)$ & $148(59)$ & \multirow[t]{2}{*}{0.226} \\
\hline $\mathrm{F}$ & $14(32)$ & $105(41)$ & \\
\hline \multicolumn{4}{|l|}{ Age, years } \\
\hline Mean \pm SD & $67 \pm 7$ & $68 \pm 8$ & 0.572 \\
\hline \multicolumn{4}{|c|}{ Familiality, n (\%) } \\
\hline Yes & $3(7)$ & $25(10)$ & \multirow[t]{2}{*}{0.521} \\
\hline No & $41(93)$ & $228(90)$ & \\
\hline \multicolumn{4}{|c|}{ Active smoking, n (\%) } \\
\hline Yes & $28(64)$ & $152(60)$ & \multirow[t]{2}{*}{0.656} \\
\hline No & $16(36)$ & $101(40)$ & \\
\hline \multicolumn{4}{|c|}{ Cardiac disease, $\mathrm{n}(\%)$} \\
\hline Yes & $15(34)$ & $75(30)$ & \multirow[t]{2}{*}{0.554} \\
\hline No & $29(66)$ & $178(70)$ & \\
\hline \multicolumn{4}{|c|}{ Hypertension, n (\%) } \\
\hline Yes & $20(45)$ & $100(39)$ & \multirow[t]{2}{*}{0.459} \\
\hline No & $24(55)$ & $153(61)$ & \\
\hline \multicolumn{4}{|c|}{ Renal diseases, n (\%) } \\
\hline Yes & $39(89)$ & $25(10)$ & \multirow[t]{2}{*}{0.763} \\
\hline No & $39(89)$ & $228(90)$ & \\
\hline \multicolumn{4}{|c|}{ Pulmonary diseases, $\mathrm{n}(\%)$} \\
\hline Yes & $12(27)$ & $62(24)$ & \multirow[t]{2}{*}{0.695} \\
\hline No & $32(73)$ & $62(24)$ & \\
\hline \multicolumn{4}{|c|}{ Obesity, n (\%) } \\
\hline Yes & $11(25)$ & 48 (19) & \multirow[t]{2}{*}{0.355} \\
\hline No & $33(75)$ & $205(81)$ & \\
\hline \multicolumn{4}{|c|}{ Diabetes, n (\%) } \\
\hline Yes & $8(18)$ & $50(20)$ & \multirow[t]{2}{*}{0.807} \\
\hline No & $36(82)$ & $203(80)$ & \\
\hline \multicolumn{4}{|c|}{ Bilirubin, mg/dl } \\
\hline Mean \pm SD & $9 \pm 5$ & $8 \pm 5$ & 0.817 \\
\hline \multicolumn{4}{|c|}{ Alkaline phosphatase, IU/l } \\
\hline Mean \pm SD & $185 \pm 93$ & $187 \pm 90$ & 0.852 \\
\hline \multicolumn{4}{|c|}{$\gamma$-Glutamyltranspeptidase, IU/1 } \\
\hline Mean \pm SD & $85 \pm 138$ & $103 \pm 200$ & 0.449 \\
\hline \multicolumn{4}{|l|}{ CEA, ng/ml } \\
\hline Mean \pm SD & $3 \pm 2$ & $3 \pm 2$ & 0.535 \\
\hline \multicolumn{4}{|l|}{$\mathrm{TPA}, \mathrm{ng} / \mathrm{ml}$} \\
\hline Mean \pm SD & $136 \pm 170$ & $141 \pm 188$ & 0.847 \\
\hline CA19-9, U/m & & & \\
\hline Mean \pm SD & $40 \pm 7$ & $42 \pm 9$ & 0.232 \\
\hline ASA & & & \\
\hline I & $8(18)$ & $73(29)$ & 0.163 \\
\hline II & $22(50)$ & $91(36)$ & \\
\hline III & $14(32)$ & $89(35)$ & \\
\hline
\end{tabular}

aRHA: Aberrant right hepatic artery; ASA: American Society of Anesthesiologists; CA19-9: carbohydrate antigen 19-9; CEA: carcinoembryonic antigen; TPA: tissue polypeptide-specific antigen. SD: standard deviation.

was used to repair accidental injury. Conditions which required $\alpha$ RHA transection were vessel tumor involvement $(n=5)$ or technical difficulties $(n=3)$. The mean operative time was $451 \pm 58$ minutes (range $=265-567$ minutes; median $=455$
Table II. Differences in tumor staging and pathology of the two groups of patients.

\begin{tabular}{lccc}
\hline & $\begin{array}{r}\alpha \text { RHA } \\
(\mathrm{n}=44), \\
\mathrm{n}(\%)\end{array}$ & $\begin{array}{c}\text { Non- } \alpha \text { RHA } \\
(\mathrm{n}=253), \\
\mathrm{n}(\%)\end{array}$ & $p$-Value \\
\hline Tumor stage & & & \\
IA & $11(25)$ & $45(18)$ & 0.592 \\
IB & $8(18)$ & $38(15)$ & \\
IIA & $23(53)$ & $155(61)$ & \\
IIB & $2(4)$ & $15(6)$ & \\
Tumor differentiation & $10(23)$ & $50(20)$ & 0.902 \\
Well & $13(29)$ & $77(30)$ & \\
Moderately & $21(48)$ & $126(50)$ & \\
Poorly or undifferentiated & & & \\
Resection margin & $42(95)$ & $220(87)$ & 0.107 \\
R0 & $2(5)$ & $33(13)$ & \\
R1 & & & \\
\hline
\end{tabular}

QRHA: Aberrant right hepatic artery; R0: curative resection; R1: microscopic residual tumor.

minutes) for group 1 and $317 \pm 27$ minutes (range $=285-510$ minutes; median $=310$ minutes) for group $2(p<0.001)$ whereas mean blood losses were $729 \pm 488 \mathrm{ml}$ (range $=390-2387 \mathrm{ml}$; median $=535 \mathrm{ml}$ ) for group 1 compared to $508 \pm 119 \mathrm{ml}$ (range $=335-930 \mathrm{ml}$; median $=480 \mathrm{ml})$ for group $2(p<0.001)$. No resection of the portal-mesenteric axis or adjacent organs was performed, and all patients underwent potentially curative surgery. Lymphadenectomy was carried out along the hepatoduodenal ligament, common hepatic artery, vena cava, superior mesenteric vein, and along the right side of the superior mesenteric artery. Trans-anastomotic catheters were seldomly placed in the pancreatic or biliary ducts according to the surgeons' preference.

Histological findings. Table II summarizes pathological findings. Clinical and pathological staging were reassessed according to the American Joint Committee on Cancer TNM staging system of pancreatic cancer (20). The mean number of lymph nodes retrieved was $14 \pm 3$ (range $=9-21$; median=14). No differences were recorded between the groups $(p=0.437)$. Resected lymph nodes were histologically positive for metastases in $42(14 \%)$ specimens (5 in group 1 and 37 in group $2 ; p=0.692)$. A total of $262(88 \%)$ patients had a microscopically tumor-negative resection margin (defined as $\leq 1 \mathrm{~mm}$ ). No statistical differences in tumor differentiation, stage and resection margin were recorded between the two groups.

Early outcome. No intraoperative death occurred of patients included in the study. Overall there were 40 (13\%) postoperative deaths within 60 days. Twenty-two (55\%) patients died due to a pancreatic fistula and seven (17\%) 
Table III. Early outcomes and statistical analysis of the post-operative complications of the two groups of patients.

\begin{tabular}{llll}
\hline & $\begin{array}{c}\alpha \text { RHA } \\
(\mathrm{n}=44), \\
\mathrm{n}(\%)\end{array}$ & $\begin{array}{c}\text { Non- } \alpha \text { RHA } \\
(\mathrm{n}=253),\end{array}$ & $p$-Value \\
$\mathrm{n}(\%)$ & \\
\hline Postoperative mortality within 60 days & $7(16)$ & $33(13)$ & 0.645 \\
Relaparotomy & $3(7)$ & $28(11)$ & 0.395 \\
Hemorrhage & $2(4)$ & $12(5)$ & 0.954 \\
Biliary fistula & $3(7)$ & $14(6)$ & 0.735 \\
Pancreatic fistula & $5(11)$ & $27(11)$ & 0.891 \\
Intra-abdominal abscess & $2(4)$ & $11(4)$ & 0.953 \\
Wound Infection & $6(14)$ & $29(12)$ & 0.680 \\
Cardiovascular complications & $3(7)$ & $15(6)$ & 0.820 \\
Cerebrovascular accident & $0(0)$ & $5(2)$ & 0.446 \\
Urinary tract infection & $3(7)$ & $18(7)$ & 0.944 \\
Pneumonia & $1(2)$ & $7(3)$ & 0.852 \\
Renal failure & $1(2)$ & $3(1)$ & 0.564 \\
Generalized sepsis & $1(2)$ & $7(3)$ & 0.852 \\
Delayed gastric emptying & $5(11)$ & $37(15)$ & 0.567 \\
\hline
\end{tabular}

aHRA: Aberrant right hepatic artery.

from hemorrhage. No differences were recorded between the groups $(p=0.782)$. Table III summarizes the postoperative complications that occurred; they were similar between the two groups. Patients in group 1 had a significantly longer stay in intensive care when compared to patients of group 2 (mean $5 \pm 2$ versus $4 \pm 2$ days, respectively; $p<0.001$ ). Overall mean postoperative length of stay was $15 \pm 4$ days (range $=10$ 30 days; median $=15$ days). Patients in group 1 had a significantly longer hospitalization when compared to those of group 2 (mean $17 \pm 5$ versus $15 \pm 3$ days, respectively; $p<0.006)$.

Long-term disease-free and survival rates. No patient had neo-adjuvant therapy. Adjuvant therapy consisted of chemotherapy alone in 189 (64\%) patients. No differences were recorded between the groups $(p=0.675)$. Radiotherapy alone or chemoradiation was never used. The mean followup was $20 \pm 13$ months (range $=1-64$ months; median $=18$ months). Twenty-four (8\%) patients were lost at a mean follow-up of $17 \pm 9$ months (range $=2-43$ months; median $=20$ months). The overall 5-year survival and disease-free rates were $19 \%$ and $10 \%$, respectively. Log-rank test showed no statistical differences between the groups $(p=0.281$ and $p=0.380$, respectively for survival and disease-free rates) (Figure 1A and B).

Multivariate analysis. Cox regression analysis was used to predict factors influencing eventual differences in 5-year survival and disease-free rates between the two groups. Variables statistically significant at univariate analysis (operative time, blood losses, length of stay in intensive care
Table IV. Multivariate analysis. Cox regression analysis to determine predictors of overall 5-year survival rate.

\begin{tabular}{lccc}
\hline Factor & Odds ratio & 95\% CI & $p$-Value \\
\hline Blood loss & 1.001 & $1.000-1.002$ & 0.001 \\
Length of stay in ICU & 1.420 & $1.300-1.550$ & 0.001 \\
Operative time & 0.998 & $0.995-1.001$ & 0.215 \\
Length of hospitalization & 0.986 & $0.938-1.036$ & 0.575 \\
\hline
\end{tabular}

CI: Confidence intervaI; ICU: Intensive Care Unit; OR: odds ratio. Model fit after Hosmer Lemeshow test, $\mathrm{df}=8, p=0.42$.

unit and overall length of hospitalization) were inserted into the model, and demonstrated that an increase in blood losses and length of stay in intensive care negatively affected 5year survival rates independently of the presence of an $\alpha$ RHA (Table IV).

\section{Discussion}

Vascular anomalies of the pancreatic region are common, and many classifications have been reported in the literature. Michels indicated as aberrant a right hepatic artery originating from the superior mesenteric artery (9). This vascular anomaly is the most frequent and the aberrant artery may run behind the pancreas, or along its ventral side or intra-parenchymally; these anatomical variations should be taken into consideration during $\mathrm{PD}(2,15,21)$.

In our series, 18 (41\%) patients had an $\alpha$ RHA running behind the head of the pancreas, and in the remaining 26 (59\%) anteriorly. We never observed an aHRA with an intraparenchymal course, which may require an en-bloc pancreatic resection (7).

Preoperative CTA imaging study can identify from $60 \%$ to $80 \%$ of vascular anomalies $(7,10-13,15,16)$. In a series of 50 patients who underwent CT scan followed by a confirmatory angiography, Chambers et al. showed a CT sensitivity, specify and accuracy of $96 \%, 87$ and $88 \%$, respectively (22). In our series, preoperative CTA identified vascular anomalies in $84 \%$ of patients. At present, angiography is a second-line examination, recommended for rare and complex vascular anomalies, providing accurate anatomical details $(10,11,23,24)$. However, it is unable to identify the relation between blood vessels and the hepatic parenchyma, essential in the preoperative study (10) and, therefore, should not be suggested for routine use $(15,25)$.

The diagnosis of an anomalous course of the artery should be preferentially made preoperatively because the intraoperative identification of vascular anatomical variation might interfere with lymphadenectomy and pancreatic resection or reconstruction, increasing the risk of vascular damage, hemorrhage and ischemic lesions $(3,10,13)$. 

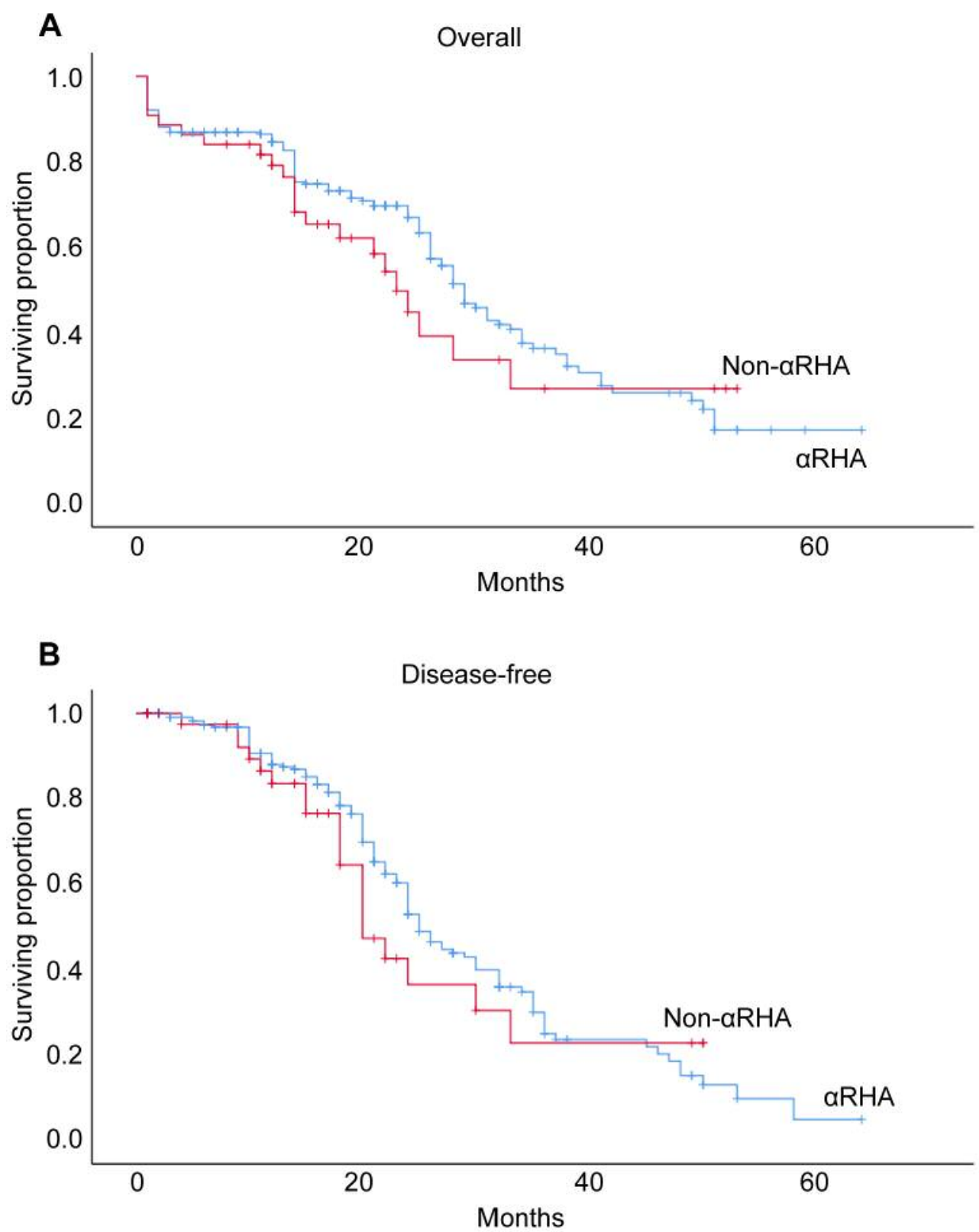

Figure 1. Cumulative 5-year overall (A) and disease-free (B) rates (crosses indicate patients censored at each point). aRHA: Aberrant right hepatic artery.

Although preoperative imaging studies permit diagnosis of aHRA with a high sensitivity and specificity, half of all aHRAs are still detected intraoperatively $(26,27)$; in our series, seven $(16 \%)$ cases were found during PD.

Many techniques to manage aHRA have been described: Dissection and preservation, or transection and reconstruction are the most used (28). Dissection and preservation of the aHA should be considered as the first-choice approach, despite its increased bleeding risk, its less suitability in cases where oncological resection are a concern, and its increased incidence in postoperative pancreatic fistula; moreover, inappropriate artery traction might increase the risk of postoperative hemorrhage $(5,11,28)$. Whenever possible, the aberrant artery should be preserved $(10,12,16,26)$, and although surgical complexity is increased, no adverse effects on safety and surgical outcomes are reported $(10,15,16)$.

Some authors have observed an increase in operative time and intraoperative blood loss in patients with $\alpha$ RHA $(5,7)$, 
which was confirmed by our results. These findings were probably due to the need to perform an $\alpha$ RHA lymphadenectomy representing an additional surgical step and greater manipulation in artery preparation, thus leading to an increase in blood loss.

In those cases, in which it was not possible to preserve $\alpha$ RHA, due to intraparenchymal artery course or neoplastic vascular infiltration, an en-bloc resection in association with arterial reconstruction is indicated to preserve the blood supply to the right hepatic lobe (7). Accidental arterial resection or small tract aHA section requires reconstruction with primary arterial stump anastomosis; a tension-free technique is mandatory to prevent anastomosis dehiscence (7). Rammohan et al. in fact observed the development of pseudoaneurysms after excessive $\alpha$ RHA traction in an attempt to save vascularization (10).

In cases in which resection of a longer arterial segment may be required, a direct reimplantation to the gastroduodenal stump is suggested; in these cases, the use of a venous or prosthetic graft represents a valid alternative ( 9 , $11,21)$. The prosthetic graft technique is characterized by an increased risk of infection, especially in a contaminated field (i.e. enteric fluid) $(18,29,30)$. We also believe that whenever the presence of vascular anomalies may require reimplantation of vessels or venous or prosthetic graft reconstruction, the competence of a general surgeon with advanced vascular capabilities is required. We disagree with Wang et al. who suggested the possibility of $\alpha$ RHA sacrifice without reconstruction in selected cases when an aberrant artery makes radical resection impossible, or when vascular resection does not result in serious clinical consequences (28). In our opinion, the artery should be always reconstructed, and the use of autologous material is to be preferred. Preoperative embolization permits improvement of blood flow through the left hepatic artery, preventing ischemic injuries, but again we are skeptical on its usefulness (10, 12, 24, 31-34). Revascularization of the $\alpha$ RHA is always possible and preoperative recognition may simplify the operative plan necessitating the aid of different specialties or abdominal surgeons with vascular abilities.

We achieved an R0 oncological grade in $96 \%$ of our patients affected with $\alpha$ RHA, whereas in the remaining patients, an R0 procedure was achieved in $87 \%$. Paradoxically, we can affirm that a more accurate dissection of the retropancreatic tissue in the presence of aHRA is performed because the artery is accurately dissected free from the surrounding tissues. Several authors have demonstrated in fact that this anatomical variation does not have a significative impact on oncological cleaning grade $(5,35)$.

Multivariate analysis has demonstrated that, independently of the presence or absence of this anatomical variation, blood loss and a long hospitalization in intensive care negatively influence long-term outcome. This indicates that a more complex and time-consuming operation (testified by a higher blood loss) and a prolonged intensive care recovery have, as already demonstrated (36), a negative impact on survival.

We are aware that our study has some limitations; firstly, the small sample size. Secondly, our series encompassed a 20-year period during which different surgeons performed operations, as well as there having been several improvements in preoperative diagnosis. Thirdly, the tradition to have abdominal and pancreatic surgeons with advanced vascular capabilities at our Center has led to a high frequency of performance of transection with re-anastomosis and vein graft.

In conclusion, the $\alpha$ RHA is the most common vascular anomaly reported during $\mathrm{PD}$, and preoperative imaging study is essential in order to plan the correct operation and to avoid vascular injuries. We observed that the preoperative identification of $\alpha$ RHA and consequent management in a high-volume center does not negatively affect long-term disease-free and overall survival rates but higher intraoperative blood loss, and longer stay in intensive care and hospitalization are predictable. Finally, our study demonstrated that an increase in blood loss and length of stay in intensive care negatively affect 5-year survival rates independently of the presence of an $\alpha$ RHA.

\section{Conflicts of Interest}

None.

\section{Authors' Contributions}

Daniele Crocetti: Conception, design and data analysis; Paolo Sapienza: Conception, design and writing the article; Paolo Ossola: analysis and interpretation of data; Mariarita Tarallo: analysis and interpretation of data; Giuseppe Cavallaro: Collection of data; Raffaelle Serra: Conception and design; Raffaele Grande: Conception and design; Andrea Mingoli: Conception, design and data analysis; Enrico Fiori: Conception and design; Giorgio De Toma: Conception and design.

\section{References}

1 Kamisawa T, Wood LD, Itoi T and Takaori K: Pancreatic cancer. Lancet 388(10039): 73-85, 2016. PMID: 26830752. DOI: 10.1016/S0140-6736(16)00141-0

2 Crocetti D, Sapienza P, Cisano C, Tarallo M, Polistena A, Venturini L, Pedullà G, De Toma G: Pancreas preserving surgery for duodenal gastrointestinal stromal tumor removal. Minerva Chir 71(5): 281-285, 2016. PMID: 27356148.

3 Balachandran A, Darden DL, Tamm EP, Faria SC, Evans DB and Charnsangavej $\mathrm{C}$ : Arterial variants in pancreatic adenocarcinoma. Abdom Imaging 33(2): 214-212, 2008. PMID: 17435979. DOI: 10.1007/s00261-007-9235-Z

4 Shinkawa H, Yasunaga H, Hasegawa K, Matsui H, Michihata N, Fushimi $\mathrm{K}$ and Kokudo N: Mortality and morbidity after 
pancreatoduodenectomy in patients undergoing hemodialysis: Analysis using a national inpatient database. Surgery 165(4): 747-750, 2019. PMID: 30424925. DOI: 10.1016/j.surg.2018. 10.009

5 Rubio-Manzanares-Dorado M, Marín-Gómez LM, AparicioSánchez D, Suárez-Artacho G, Bellido C, Álamo JM, SerranoDíaz-Canedo J, Padillo-Ruiz FJ, Gómez-Bravo MÁ: Implication of the presence of a variant hepatic artery during the Whipple procedure. Rev Esp Enferm Dig 107(7): 417-422, 2015. PMID: 26140634.

6 Hiatt JR, Gabbay J and Busuttil RW: Surgical anatomy of the hepatic arteries in 1000 cases. Ann Surg 220(1): 50-52, 1994. PMID: 8024358.

7 Jah A, Jamieson N, Huguet E and Praseedom R: The implications of the presence of an aberrant right hepatic artery in patients undergoing a pancreaticoduodenectomy. Surg Today 39(8): 669-674, 2009. PMID: 19639433. DOI: 10.1007/s00595009-3947-3

8 Eshuis WJ, Olde Loohuis KM, Busch OR, van Gulik TM and Gouma DJ: Influence of aberrant right hepatic artery on perioperative course and longterm survival after pancreatoduodenectomy. HPB 13(3): 161-167, 2011. PMID: 21309932. DOI: 10.1111/j.1477-2574.2010.00258.x

9 Michels NA: Newer anatomy of the liver and its variant blood supply and collateral circulation. Am J Surg 112(3): 337-347, 1966. PMID: 5917302.

10 Rammohan A, Palaniappan R, Pitchaimuthu A, Rajendran K, Perumal SK, Balaraman K, Ramasamy R, Sathyanesan J and Govindan M: Implications of the presence of an aberrant right hepatic artery in patients undergoing pancreaticoduodenectomy World J Gastrointest Surg 6(1): 9-13, 2014. PMID: 24627736. DOI: $10.4240 /$ wjgs.v6.i1.9

11 Venara A, Pittet O, Lu TL, Demartines N and Halkic N: Aberrant right hepatic artery with a prepancreatic course visualized prior to pancreaticoduodenectomy. J Gastrointest Surg 17(5): 1024-1026, 2013. PMID: 23288717. DOI: 10.1007/s11605-012-2127-8

12 Shukla PJ, Barreto SG, Kulkarni A, Nagarajan G and Fingerhut A: Vascular anomalies encountered during pancreatoduo-denectomy: Do they influence outcomes? Ann Surg Oncol 17(1): 186-193, 2010. PMID: 19838756. DOI: 10.1245/s10434-009-0757-1

13 Ichida A, Sakamoto Y, Akahane M, Ishizawa T, Kaneko J, Aoki T, Hasegawa K, Sugawara Y and Kokudo N: Successful case of pancreaticoduodenectomy with resection of the hepatic arteries preserving a single aberrant hepatic artery for a pancreatic neuroendocrine tumor: Report of a case. Surg Today 45(3): 363368, 2015. PMID: 24477525. DOI: 10.1007/s00595-014-0837-0

14 De Felice F, Musio D, Raffetto N and Tombolini V: Neoadjuvant strategy as initial treatment in resectable pancreatic cancer: concrete evidence of benefit. Anticancer Res 34(9): 4673-4676, 2014. PMID: 25202043.

15 Lee JM, Lee YJ, Kim CW, Moon KM and Kim MW: Clinical implications of an aberrant right hepatic artery in patients undergoing pancreaticoduodenectomy. World J Surg 33(8): 1727-1732, 2009. PMID: 19459000. DOI: 10.1007/s00268-0090063-X

16 Stauffer JA, Bridges MD, Turan N, Nguyen JH and Martin JK: Aberrant right hepatic arterial anatomy and pancreaticoduodenectomy: recognition, prevalence and management. HPB 11(2): 161-165, 2009. PMID: 19590642. DOI: 10.1111/j.14772574.2009.00037.x
17 von Elm E, Altman DG, Egger M, Pocock SJ, Gøtzsche PC, Vandenbroucke JP and STROBE Initiative: The Strengthening the Reporting of Observational Studies in Epidemiology (STROBE) Statement: Guidelines for reporting observational studies. Int J Surg 12(12): 1495-1499, 2014. PMID: 25046131. DOI: $10.1016 /$ j.ijsu.2014.07.013

18 American Society of Anesthesiologists. ASA Physical Status Classification System. Last approved by ASA House of Delegates on October 15, 2014. http://www.asahq.org/ / media/ sites/asahq/ files/public/resources/standards-guidelines/asa-physical-statusclassification-system.pdf. Last accessed on 4th June 2019.

19 Bassi C, Dervenis C, Butturini G, Fingerhut A, Yeo C, Izbicki J, Neoptolemos J, Sarr M, Traverso W, Buchler M and International Study Group on Pancreatic Fistula Definition: Postoperative pancreatic fistula: An International Study Group (ISGPF) definition. Surgery 138(1): 8-13, 2005. PMID: 1600 3309. DOI: 10.1016/j.surg.2005.05.001

20 Kakar S, Pawlik TM, Allen PJ and Vauthey JN: Exocrine pancreas. In: AJCC Cancer Staging Manual. Amin MB, Edge S, Greene F, Byrd DR, Brookland RK, Washington MK, Gershenwald JE, Compton CC, Hess KR, Sullivan DC, Jessup JM, Brierley JD, Gaspar LE, Schilsky RL, Balch CM, Winchester DP, Asare EA, Madera M, Gress DM and Meyer LR (eds.): AJCC Cancer Staging Manual, 8th ed. New York, NY: Springer-Verlag, pp. 337-347, 2017.

21 Noussios G, Dimitriou I, Chatzis I and Katsourakis A: The main anatomic variations of the hepatic artery and their importance in surgical practice: review of the literature. J Clin Med Res 9(4): 248-252, 2017. PMID: 28270883. DOI: 10.14740/jocmr2902w

22 Chambers TP, Fishman EK, Bluemke DA, Urban B and Venbrux AC: Identification of the aberrant hepatic artery with axial spiral CT. J Vasc Interv Radiol 6(6): 959-964, 1995. PMID: 8850677.

23 Yang F, Long J, Fu DL, Jin C, Yu XJ, Xu J and Ni QX: Aberrant hepatic artery in patients undergoing pancreaticoduodenectomy. Pancreatology 8(1): 50-54, 2008. PMID: 18230918. DOI: $10.1159 / 000114867$

24 Rong GH and Sindelar WF: Aberrant peripancreatic arterial anatomy. Considerations in performing pancreatectomy for malignant neoplasms. Am Surg 53(12): 726-729, 1987. PMID: 3425998.

25 Winston CB, Lee NA, Jarnagin WR, Teitcher J, DeMatteo RP, Fong $\mathrm{Y}$ and Blumgart LH: CT angiography for delineation of celiac and superior mesenteric artery variants in patients undergoing hepatobiliary and pancreatic surgery. Am J Roentgenol 189(3): 567573, 2007. PMID: 17715102. DOI: 10.2214/AJR.07.2078

26 El Amrani M, Pruvot FR and Truant S: Management of the right hepatic artery in pancreaticoduodenectomy: a systematic review. J Gastrointest Oncol 7(2): 298-305, 2016. PMID: 27034799. DOI: $10.3978 /$ j.issn.2078-6891.2015.093

27 Turrini O, Wiebke EA, Delpero JR, Viret F, Lillemoe KD and Schmidt CM: Preservation of replaced or accessory right hepatic artery during pancreaticoduodenectomy for adenocarcinoma: impact on margin status and survival. J Gastrointest Surg 14(11): 1813-1819, 2010. PMID: 20697832. DOI: 10.1007/s11605-0101272-1

28 Wang L, Xu J, Sun D and Zhang Z: Aberrant hepatic arteries running through pancreatic parenchyma encountered during pancreatoduodenectomy: Two rare case reports and strategies for surgical treatment. Medicine 95(49): e3867, 2016. PMID: 27930504. DOI: 10.1097/MD.0000000000003867 
29 Sapienza P, Napoli F, Tartaglia E, Venturini L, Sterpetti AV, Brachini G, Gazzanelli S and Mingoli A: Infection of prosthetic patches after femoral endarterectomy: an unreported complication. Ann Vasc Surg 56: 11-16, 2018. PMID: 30342213. DOI: $10.1016 /$ j.avsg.2018.07.069

30 Mingoli A, Sapienza P, di Marzo L, Sgarzini G, Burchi C, Modini $\mathrm{C}$ and Cavallaro A: Management of abdominal aortic prosthetic graft infection requiring emergent treatment. Angiology 48(6): 491-495, 1997. PMID: 9194534. DOI: $10.1177 / 000331979704800603$

31 Nakano H, Kikuchi K, Seta S, Katayama M, Horikoshi K, Yamamura $\mathrm{T}$ and Otsubo T: A patient undergoing pancreaticoduodenectomy in whom involved common hepatic artery anomalously arising from the superior mesenteric artery was removed and reconstructed. Hepatogastroenterology 52(66): 1883-1885, 2005. PMID: 16334799.

32 Yamamoto S, Kubota K, Rokkaku K, Nemoto T and Sakuma A: Disposal of replaced common hepatic artery coursing within the pancreas during pancreatoduodenectomy: report of a case. Surg Today 35(11): 984-987, 2005. PMID: 16249858. DOI: 10.1007/s00595-005-3040-5

33 Woods MS and Traverso LW: Sparing a replaced common hepatic artery during pancreaticoduodenectomy. Am Surg 59(11): 719-721, 1993. PMID: 7902051
34 Miyamoto N, Kodama Y, Endo H, Shimizu T, Miyasaka K, Tanaka E, Anbo Y, Hirano S, Kondo S and Katoh H: Embolization of the replaced common hepatic artery before surgery for pancreatic head cancer: report of a case. Surg Today 34(7): 619-622, 2004. PMID: 15221560. DOI: 10.1007/s00595004-2785-6

35 Kim PT, Temple S, Atenafu EG, Cleary SP, Moulton CA, McGilvray ID, Gallinger S, Greig PD and Wei AC: Aberrant right hepatic artery in pancreaticoduodenectomy for adenocarcinoma: impact on resectability and postoperative outcomes. HPB 16(3): 204-211, 2014. PMID: 23782313. DOI: $10.1111 / \mathrm{hpb} .12120$

36 Hartwig W, Gluth A, Hinz U, Koliogiannis D, Strobel O, Hackert T, Werner J and Büchler MW: Outcomes after extended pancreatectomy in patients with borderline resectable and locally advanced pancreatic cancer. Br J Surg 103(12): 1683-1694, 2016. PMID: 27686238. DOI: 10.1002/bjs.10221

Received March 21, 2019

Revised June 4, 2019

Accepted June 6, 2019 